\title{
The effect of additives on bending strenght of pultruded hybrid reinforced resol type phenolic composite
}

\begin{abstract}
Pultrusion manufacturing process is a well established technique for the cost-effective production of high-modulus and lightweight composite materials having constant crosssectional profiles. A study was carried out to analyze the effect of additives on bending strength of pultruded hybrid reinforced resol type phenolic composite. Glassfibre roving and kenaf fibre hybrid were reinforced in resol type phenolic. A series of bending tests were performed by varying the loading percentage of two type's pultruded fibres, without additives and with additives. From the results, it was found that the modulus of strength of composites with additives display higher values as compared to composite without additives. The presence of additives were able to synergistically interact with both fibres and finally improve the interaction between them. Analysis of the fracture surface from the bending test were carried out using Dino-Lite digital microscope.
\end{abstract}

Keyword: Bending test; Glass fiber; Hybrid composite; Kenaf fiber; Phenolic resin; Pultruded 